\title{
Recurrent Testicular Lymphoma
}

National Cancer Institute

\section{Source}

National Cancer Institute. Recurrent Testicular Lymphoma. NCI Thesaurus. Code C138021.

The reemergence of testicular lymphoma after a period of remission. 